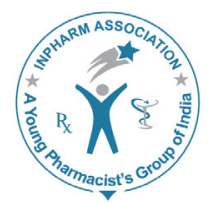

\title{
Signal Detection for Cyclophosphamide: Canadian Adverse Reaction Monitoring Program (CADRMP)
}

\author{
Singhal Sharwan*1 and Bhaswat Chakraborty ${ }^{2}$ \\ ${ }^{1}$ Department of Clinical Research, Cadila Pharmaceuticals Ltd., Ahmedabad, India \\ ${ }^{2}$ Department of Pharmacology, Institute of Pharmacy, Nirma University, Sarkhej-Gandhinagar Highway, \\ Chandlodia, Gota, Ahmedabad, Gujarat, India.
}

\begin{abstract}
Objective: The objective of the study was to identify possible toxic signal induced by cyclophosphamide treatment by searching database from Canadian Adverse Reaction Monitoring Program (CADRMP). Methods: A total of 10429 reports of patients between January 1970 to March 2010 were downloaded from CADRMP website. These reports contained information of adverse events associated with all other drugs inclusive of cyclophosphamide. Adverse drug reaction (ADR) signal detection were determined by proportional reporting ratio (PRR), reporting odds ratio (ROR), PRR calculated by chisquare statistics, $95 \%$ confidence interval of PRR, observed to expected (O/E) ratio and De Mouchel method calculated PRR. Information component (IC) was given by Bayesian confidence propagation neural network. (As per regulatory criteria, $P R R \geq 2, R O R \geq 1$, chi-square statistics calculated $P R R \geq 4$ and lower bound of $95 \% \mathrm{Cl}$ of $P R R \geq 1$ to consider particular adverse drug reaction as a signal. Further by BCPNN method, if IC-2SD $\leq 0$ then that drug-ADR pair considered as no signal; if $0<1 C-2 S D \leq 1.5$, then that drug-ADR pair considered as weak signal; if $1.5<1 C-2 S D \leq 3.0$, then that drug-ADR pair considered as middle signal; if IC-2SD > 3.0, then that drug-ADR pair considered as strong signal). Results: A total of 108 reports of cyclophosphamide-induced neutropenia were reported in CADRMP database. The PRR was found to be 4.7396 and by the Du Mouchel method it was 3.9310. Further, the PRR calculated by chi-square statistics was 236.02518. The lower and upper limits of $95 \% \mathrm{Cl}$ of PRR was found to be 1.3484 and 1.7634 , respectively. The O/E ratio was found to be 3.9322 and $R O R$ was found to be 4.9704 . The value of $P R R \geq 2, R O R \geq 1$, chi-square statistics calculated $P R R \geq 4$ and lower limit of $95 \% \mathrm{Cl}$ of PRR $\geq 1$ indicates signal for neutropenia caused by cyclophosphamide. The value of IC-2SD was 1.6852 indicates middle signal for cyclophosphamide-induced neutropenia. The signal of neutropenia coupled with cyclophosphamide was found potent enough to cause neutropenia in Canadian population.
\end{abstract}

Key words: Bayesian confidence propagation neural network, Cyclophosphamide, Neutropenia, Proportional reporting ratio, Signal detection.

\section{INTRODUCTION}

Signal detection in pharmacovigilance comprises the processes of selection of a drug-adverse event association of possible interest; the preliminary assessment of the

\begin{tabular}{|c|l|}
\hline \multicolumn{2}{|c|}{ Access this article online } \\
\hline \multirow{2}{*}{ Journal Sponsor } & \multirow{2}{*}{$\begin{array}{l}\text { Website: } \\
\text { www.jyoungpharm.org }\end{array}$} \\
\cline { 2 - 2 } & \\
\cline { 2 - 2 } & DOI: \\
& $10.5530 /$ jyp.2015.4.8 \\
\hline
\end{tabular}

available evidence; and a follow-up of how the signal develops. In the currently used automated systems, the computer selects drug-adverse event pairs that stand out against the background of the database, according prefixed statistical criteria, for example, using proportional reporting ratio (PRR) or, as is the case at the UMC, the information component (IC) calculated by a Bayesian Confidence Propagation Neural Network (BCPNN). Once the computer has at a given moment identified the associations that meet the quantitative criterion, individual assessors have to select those associations that deserve

\footnotetext{
*Address for correspondence:

Mr. Sharwan Singhal, CRO-Cadila Pharmaceuticals Ltd., 1389, Trasad Road, Dholka-387810, Dist. Ahmedabad, Gujarat, India.

E-mail: sharwansinghal@rediffmail.com
} 


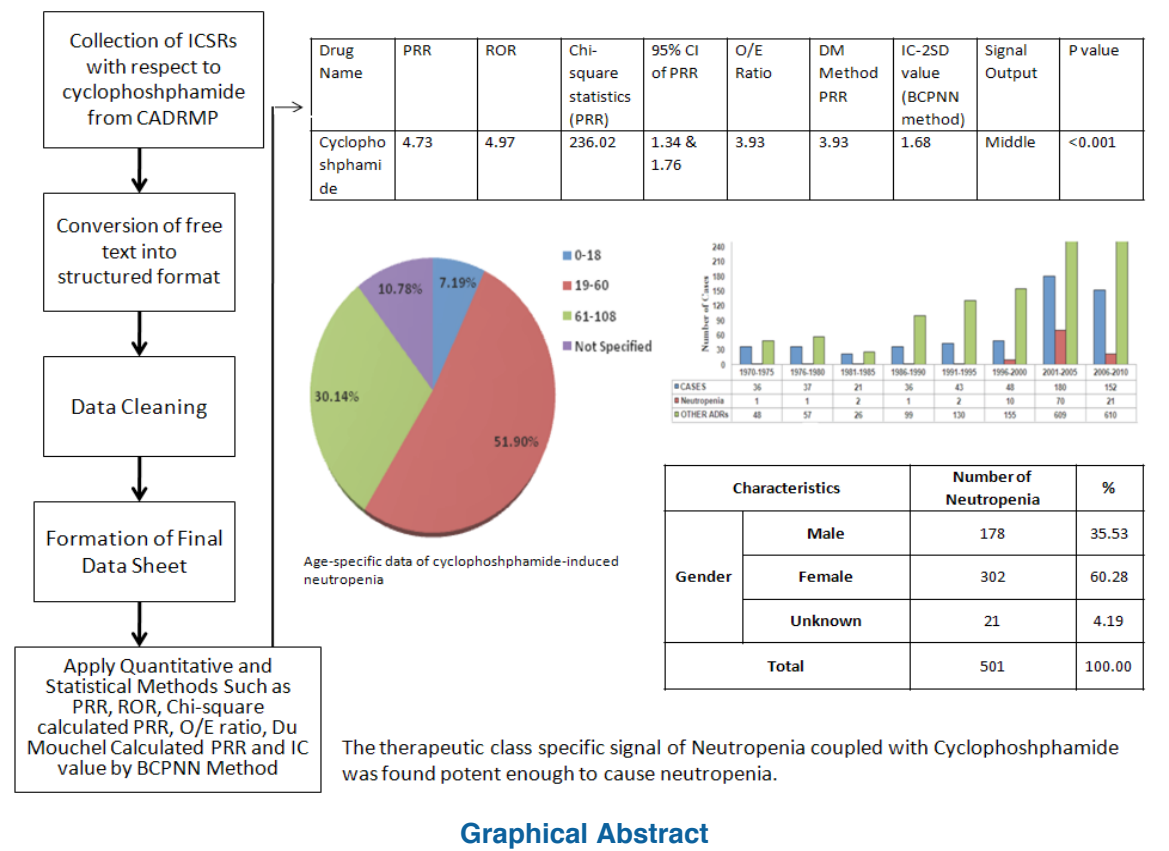

further preliminary attention. From now on the human mind has to decide whether the association is likely or not to represent a true signal and needs further examination. ${ }^{1}$

Cyclophosphamide is an inactive pro-drug that requires enzymatic and chemical activation; the resultant nitrogen mustard produces the interstrand and intrastrand DNA cross links that account for its cytotoxic properties. The major mechanism of cyclophosphamide detoxification involves aldehyde dehydrogenase; cells with high proliferative potential express high levels of aldehyde dehydrogenase and as a consequence are relatively resistant to cyclophosphamide. Cyclophosphamide, in combination with other antineoplastic agents, is used for the treatment of various cancers, including breast, lymphoid and pediatric malignancies. Cyclophosphamide is also widely used in bone marrow transplantation 'conditioning' and 'mobilization' regimens, and for the treatment of different autoimmune conditions. The toxic effects of cyclophosphamide include bone marrow suppression, cardiac and gonadal toxicity, hemorrhagic cystitis and carcinogenesis, with cumulative dose being the principal risk factor. ${ }^{2}$

Bone marrow suppression is the most common toxic effect of cyclophosphamide. Neutropenia is dose dependent. Patients treated with low dose cyclophosphamide should be monitored closely, although they rarely develop significant neutropenia. Leukopenia, thrombocytopenia and anemia are common after high dose cyclophosphamide administration. ${ }^{2}$ Rapid hematologic recovery invariably occurs within 2-3 weeks in patients with normal bone marrow reserve; regardless of the dose. ${ }^{2}$ The objective of the study was to identify possible toxic signal detection (SD) of cyclophosphamide by searching database from Canadian Adverse Reaction Monitoring Program (CADRMP).

\section{MATERIALS AND METHODS}

\section{Data collection from public database}

The CADRMP is the Health Canada post-marketing surveillance program which collects and assesses suspected adverse reaction reports for Canadian marketed health products such as cyclophosphamide. Data was extracted from Canadian Adverse Drug Reaction Monitoring Program. For extraction following sections were serially accessed from health Canada website (http://www.hc-sc. gc.ca/index-eng.php). ${ }^{3}$ In the section of Canada vigilance program, the CADRMP online database was extracted.

\section{Procedure followed for signal detection}

Individual Case Safety Reports (ICSRs) in this database were collected from the official website of Health Canada. The text freely available was converted into a structured format. In the structured format, statistical methods were applied to calculate an actual measure of signals. Therapeutic class-specific SD calculations were then carried out as shown in Figure 1. For analysis of detection of signals by different methods are reported. These methods of calculations were selected following a systematic literature review. ${ }^{4-6}$ In the present study, attempt was made to maintain the originality of data collected from CADRMP database while computing actual SD. 


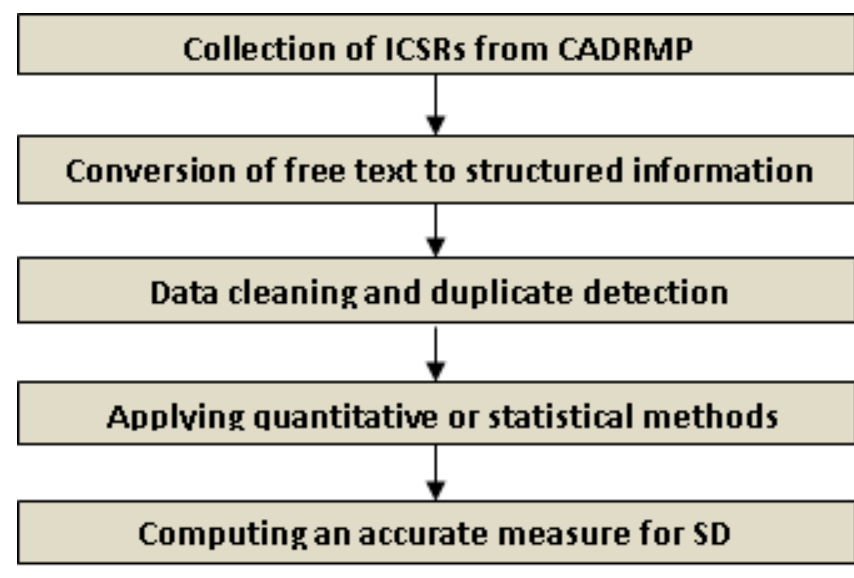

Figure 1: Procedure followed for Signal Detection by statistical and quantitative methods

\section{Calculation of signal detection}

\section{Disproportional ity}

These are the frequency or relative frequency of a particular drug-event pair. The signal would be considered significant if the statistics from different calculations such as Proportional Reporting Ratio (PRR), Reporting Odds Ratio (ROR), PRR calculated by chi-square statistics, the 95\% confidence interval for PRR (lower limit and upper limit), the observed-to-expected (O/E ratio) and DuMouchel method calculated PRR exceeded a certain value ((As per regulatory criteria, $\mathrm{PRR} \geq 2, \mathrm{ROR} \geq 1$, chi-square statistics calculated PRR $\geq 4$ and lower bound limit of $95 \%$ CI of $\mathrm{PRR} \geq 1$ to consider particular adverse drug reaction as a signal. Further by BCPNN method, if $\mathrm{IC}-2 \mathrm{SD} \leq 0$ then that drug-ADR pair considered as no signal; if $0<$ $\mathrm{IC}-2 \mathrm{SD} \leq 1.5$, then that drug-ADR pair considered as weak signal; if $1.5<\mathrm{IC}-2 \mathrm{SD} \leq 3.0$, then that drug-ADR pair considered as middle signal; if $\mathrm{IC}-2 \mathrm{SD}>3.0$, then that drug-ADR pair considered as strong signal), then the signal would be considered significant. ${ }^{5}$

\section{PRR calculation}

As shown in Table 1 and 2 , a $2 * 2$ contingency table was prepared to capture the incidences of neutropenia (targeted event Y) and all other events for the targeted drug X, i.e., cyclphosphamide, and all other drugs in the database to calculate PRR. ${ }^{4}$ After that, the PRR was calculated as follows:

$$
\operatorname{PRR}=\frac{a / a+b}{c / c+d}
$$

$\mathrm{a}=$ Targeted event $(\mathrm{Y})$ associated with targeted drug

$\mathrm{b}=$ Other adverse drug reactions (ADRs) associated with targeted drug

\begin{tabular}{|c|c|c|}
\hline Drug Name & Neutropenia & Not Neutropenia \\
\hline Cyclophosphamide & 108 & 1734 \\
\hline $\begin{array}{c}\text { Not } \\
\text { Cyclophosphamide }\end{array}$ & 393 & 31355 \\
\hline
\end{tabular}

\begin{tabular}{|cc|}
\hline Table 2: Cyclophosphamide database reports details & Numbers \\
\hline $\begin{array}{c}\text { Description } \\
\text { Total Reports included in database } \\
\text { Neutropenia associated with } \\
\text { Cyclophosphamide }\end{array}$ & 10429 \\
\hline $\begin{array}{c}\text { Other ADR's reported with } \\
\text { Cyclophosphamide }\end{array}$ & 108 \\
\hline $\begin{array}{c}\text { Neutropenia associated with other than } \\
\text { Cyclophosphamide }\end{array}$ & 393 \\
\hline $\begin{array}{c}\text { Other ADR's associated with other than } \\
\text { Cyclophosphamide }\end{array}$ & 31355 \\
\hline
\end{tabular}

$\mathrm{c}=$ Targeted event $(\mathrm{Y})$ associated with other than targeted drug

$\mathrm{d}=$ Other adverse drug reactions (ADRs) with other than targeted drug

\section{$R O R$ calculation}

The procedure followed to calculate ROR was similar to that of the PRR method. ${ }^{4}$ The same contingency table (Table 1 and 2) prepared for PRR, was also followed in the case of ROR calculations. The ROR was calculated as follows:

$$
\operatorname{ROR}=\frac{\mathrm{a} / \mathrm{b}}{\mathrm{c} / \mathrm{d}}
$$

$\mathrm{a}=$ Targeted event $(\mathrm{Y})$ associated with targeted drug

$\mathrm{b}=$ Other adverse drug reactions (ADRs) associated with targeted drug

$\mathrm{c}=$ Targeted event $(\mathrm{Y})$ associated with other than targeted drug

$\mathrm{d}=$ Other adverse drug reactions (ADRs) with other than targeted drug

\section{The Chi-square $\left(\chi^{2}\right)$ statistics calculated PRR}

The chi-square statistics was applied to test the independence of categorical variables. ${ }^{6} \chi^{2}$ was used as an alternative measure of heterogeneity in the contingency table which built with the medicinal product $\mathrm{X}$ and the adverse event Y. PRR calculated by chi-square statistics was calculated as follows:

$$
\text { Chi }- \text { Square }=\sum \frac{(\text { Observed }- \text { Expected })^{2}}{(\text { Expected })}
$$


95\% confidence interval of the PRR calculation

The standard error of the natural logarithm of the PRR was estimated based on the following formula:

$$
\mathrm{SE}=\sqrt{1 / A+1 / C-1 /(A+B)-1 /(C+D)}
$$

$\mathrm{A}=$ Targeted event $(\mathrm{Y})$ associated with targeted drug

$\mathrm{B}=$ Targeted event $(\mathrm{Y})$ associated with other than targeted drug

$\mathrm{C}=$ Targeted event $(\mathrm{Y})$ and Other adverse drug reactions (ADRs) associated with targeted drug

$\mathrm{D}=$ Targeted event $(\mathrm{Y})$ and Other adverse drug reactions (ADRs) associated with other than targeted drug

The 95\% CI for $\ln$ (PRR) was then estimated as $\ln$ (PRR) $\pm 1.96 \mathrm{SE}$, and its exponential was taken. ${ }^{7}$ Lower and upper limits of 95\% CI for PRR $=\{\mathrm{PRR} / \exp (1.96 \mathrm{SE}), \mathrm{PRR} /$ $\exp (1.96 \mathrm{SE})\}^{6}$

The observed-to-expected (O/E) ratio calculation ${ }^{8}$

The $\mathrm{O} / \mathrm{E}$ was calculated as follows:

$$
O E=\frac{A /(A+B)}{(A+C) /(A+B+C+D)}
$$

$\mathrm{A}=$ Targeted event $(\mathrm{Y})$ associated with targeted drug

$\mathrm{B}=$ Other adverse drug reactions (ADRs) associated with targeted drug

$\mathrm{C}=$ Targeted event $(\mathrm{Y})$ associated with other than targeted drug

$\mathrm{D}=$ Other adverse drug reactions (ADRs) with other than targeted drug

Du Mouchel Method for PRR calculation

This method was based on $2 * 2$ contingency table values as well as the ratio of values of $A$ and expected $A$ was taken into consideration for calculations. The PRR as per Du Mouchel Method was calculated as per below equation:

$\operatorname{PRR}=\frac{A /(A+I}{(A+C) /} E(a)=\frac{(A+B) /(A+C)}{N} \operatorname{PRR}=\frac{A}{E(a)}$ $\mathrm{A}=$ Targeted event $(\mathrm{Y})$ associated with targeted drug

$\mathrm{B}=$ Other adverse drug reactions (ADRs) associated with targeted drug

$\mathrm{C}=$ Targeted event $(\mathrm{Y})$ associated with other than targeted drug
$\mathrm{D}=$ Other adverse drug reactions (ADRs) with other than targeted drug

$\mathrm{N}=$ Total sum of adverse drug reactions associated with drug and other than targeted drug

Signal Detection by Bayesian Confidence Propagation Neural Network (BCPNN)

BCPNN has been chosen for ADR signal detection, which realized through calculating the information components (IC) compared the calculating IC value with the BCPNN corresponding evaluation standard of signal detection to judge if the signal established or not. ${ }^{7}$ The specific algorithm of BCPNN as follows:

IC $=\log 2\left(\frac{(\text { Ncomb }+0.5)}{\text { Nadr } / \text { Ntotal } * \text { Ndrug }+0.5)}\right)$

$E(I C)=\log 2 \frac{\gamma(C i+\lambda)}{N+\gamma}=\log 2(C i+\lambda)(N+\delta)(N+\mu) /(N+\gamma)(C j+\alpha)(C k+\beta)$

$\boldsymbol{\gamma}=\boldsymbol{\lambda}(\mathrm{N}+\boldsymbol{\delta})(\mathrm{N}+\Pi) /(\mathrm{Cj}+\boldsymbol{\alpha})(\mathrm{Ck}+\boldsymbol{\beta})$

$V(\mathrm{IC})=\mathrm{N}-\mathrm{Ci}+\gamma-\delta /(\mathrm{Ci}+\lambda)(1+\mathrm{N}+\lambda)+\mathrm{N}-\mathrm{Cj}+\delta-\alpha /(\mathrm{Cj}+\alpha)(1$ $+N+\delta)+N-C k+n-\beta /(C j+\beta)(1+N+\pi)$

$\mathrm{N}_{\text {comb }}\left(\mathrm{C}_{\mathrm{i}}\right)=\mathrm{A}=$ Targeted event $(\mathrm{Y})$ associated with targeted drug

$\mathrm{N}_{\text {drug }}\left(\mathrm{C}_{\mathrm{j}}\right)=\mathrm{A}+\mathrm{B}=$ Targeted event $(\mathrm{Y})$ and other adverse drug reactions (ADRs) associated with targeted drug

$\mathrm{N}_{\text {adr }}\left(\mathrm{C}_{\mathrm{k}}\right)=\mathrm{A}+\mathrm{C}=$ Targeted event $(\mathrm{Y})$ associated with drug and other than targeted drug

$\mathrm{N}_{\text {tot }}(\mathrm{C})=\mathrm{A}+\mathrm{B}+\mathrm{C}+\mathrm{D}=$ Total sum of adverse drug reactions associated with drug and other than targeted drug

And considering: $\lambda=1, \alpha=\beta=1, \eta=\delta=2$. Following different formulas used for signal detection by BCPNN methods

Statistical calculation

The statistical significance of PRR, ROR, Chi-square calculated PRR, O/E ratio, Du-Mouchel calculated PRR and information component statistics by BCPNN method was based on regulatory guidelines. ${ }^{6}$

\section{RESULTS}

Proportional reporting ratio (PRR) and Reporting odds ratio (ROR) The total of 10429 patient's reports were extracted from CADRMP. $1842(100 \%)$ reports of adverse event associated 


\begin{tabular}{|c|c|c|c|}
\hline Drug Name & Neutropenia & $\begin{array}{c}\text { Not } \\
\text { Neutropenia }\end{array}$ & Total \\
\hline Cyclophosphamide & 108 & 1734 & 1842 \\
\hline $\begin{array}{c}\text { Not } \\
\text { Cyclophosphamide }\end{array}$ & 393 & 31355 & 31748 \\
\hline Total & 501 & 33089 & 33590 \\
\hline
\end{tabular}

with cyclophosphamide inclusive neutropenia were noted. The relevant details for calculation of PRR and ROR are mentioned in Table 1 and 2. The signal detected with the help of "proportional reporting ratio" for neutropenia associated with cyclophosphamide was found to be 4.7396 and "reporting odds ratio" for neutropenia associated with cyclophosphamide was found to be 4.9704 . However, the PRR with the help of the Du Mouchel Method was found to be 3.9310. As per above results, the value of PRR was $\geq 2$ and value of ROR was $\geq 1$ indicate toxic signal for neutropenia associated with cyclophosphamide.

Chi-square statistics calculated PRR

The relevant details for calculation of Chi-square statistics calculated PRR is mentioned in Table 3. The chi-square statistics calculated PRR was 236.02518. The value of chi-square statistics calculated PRR was $\geq 4$ for cyclophosphamide which also indicates toxic signal for neutropenia associated with cyclophosphamide.

95\% Confidence interval for PRR

The lower limit of 95\% Confidence Interval of PRR was found to be 1.3484 and Upper limit was found to be 1.7634 . 95\% Confidence interval of PRR has been computed as per mentioned below steps:

$$
\begin{aligned}
\mathrm{SE} & =\sqrt{1 / \mathrm{A}+1 / \mathrm{C}-1 /(\mathrm{A}+\mathrm{B})-1 /(\mathrm{C}+\mathrm{D})} \\
& =\sqrt{1 / 108+1 / 393-1 / 1842-1 / 31748} \\
& =\sqrt{0.00925+0.002544-0.00054-0.000031} \\
& =\sqrt{0.01179-0.000571} \\
& =\sqrt{0.01121}
\end{aligned}
$$

$\mathrm{SE}=0.1058$

Therefore, 1.96 SE=0.1058x1.96

$$
=0.2075
$$

Hence, 95\% Confidence Interval for

$$
\begin{aligned}
\mathrm{PRR} & =\ln (\mathrm{PRR}) \pm 1.96 \mathrm{SE} \\
& =\ln (4.7396) \pm 1.96(0.1058) \\
& =1.5559 \pm 0.2075 \\
& =1.3484 \text { and } 1.7634
\end{aligned}
$$

The lower limit of $95 \%$ CI of PRR was $\geq 1$ for cyclophosphamide-induced neutropenia.

\section{Observed to expected ratio}

The Observed-to-expected ratio of PRR was found to be 3.9322. Observed to expected ratio has been computed as per mentioned below steps:

$$
\begin{aligned}
\mathrm{OE} & =\frac{108 /(108+1734)}{(108+393) /(108+1734+393+31355)} \\
& =\frac{108 / 1842}{501 / 33590}
\end{aligned}
$$$$
\mathrm{OE}=3.9322
$$

Data by gender and age

The data obtained from CADRMP were stratified by years (Figure 2), age (Figure 3) and gender (Table 4). Highest numbers of neutropenia were reported between 2001 to 2005. Females were more prone to neutropenia associated with cyclophosphamide as high as $60.28 \%$ as compared to $35.53 \%$ of males. Also, when stratified on the basis of age group it clearly indicated that neutropenia associated with cyclophosphamide prevalence was high in age group of; $19-60$ years with $51.90 \%$; while $30.14 \%$ in $60-108$ years and $7.19 \%$ in $0-18$ years age group.

Signal Detection by Bayesian Confidence Propagation Neural Network

The details of signal detection by BCPNN method and relevant parameters for cyclophosphamide were mentioned in Table 5 and 6 . The value of IC is 1.9811, the value of IC-2SD is observed 1.3484 means middle signal for neutropenia at the Canadian data base.

The conclusive summary of signal detection for cyclophosphamide was mentioned in Table 7.

Adverse event evaluation

All patients reported at least one adverse event (AE). Listing of AEs was done according to the system or organ class (Table 8). 


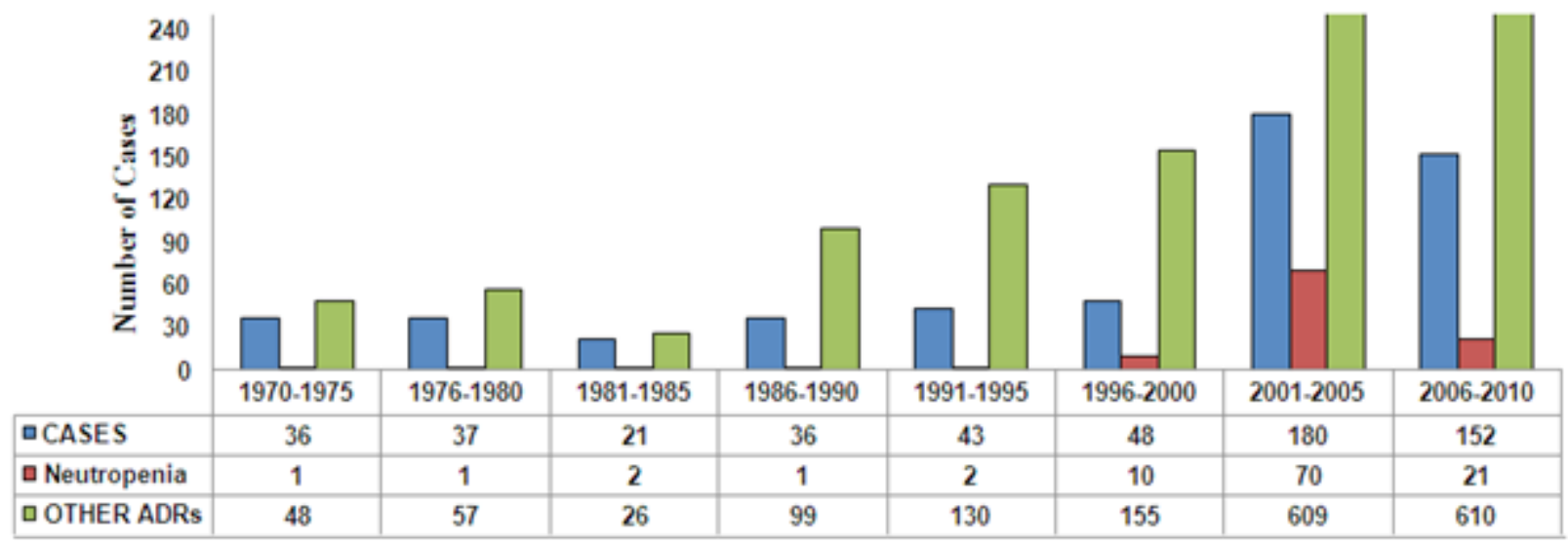

Figure 2: Year Specific Data of Cyclophosphamide-Induced Neutropenia

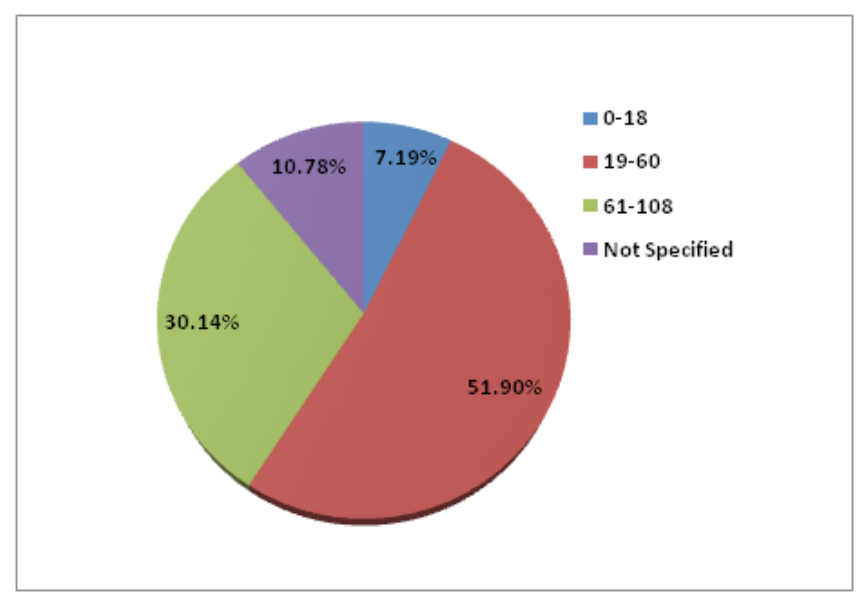

Table 4: Cases of Neutropenia as per gender specific

\begin{tabular}{cccc} 
Characteristics & Number of Neutropenia & $\%$ \\
\multirow{3}{*}{ Gender } & Male & 178 & 35.53 \\
& Female & 302 & 60.28 \\
& Unknown & 21 & 4.19 \\
\cline { 2 - 3 } & Total & 501 & 100.00
\end{tabular}

Table 5: Cyclophosphamide-Data obtained from Canadian adverse drug reaction monitoring program database to calculate signal detection by BCPNN method

$\begin{array}{ccc}\text { Drug Name } & \text { Neutropenia } & \text { Not } \\ \text { Cyclophosphamide } & 108 & 1734 \\ \text { Not Cyclophosphamide } & 393 & 31355\end{array}$

Figure 3: Age Specific Data of Cyclophosphamide-Induced Neutropenia

\begin{tabular}{|c|c|c|c|c|c|c|c|}
\hline Drug Name & IC & $\gamma$ & $E(I C)$ & V (IC) & SD & IC-2 SD & $I C+2$ SD \\
\hline Cyclophosphamide & 1.9811 & 1219.67092 & 1.9332 & 0.2189 & 0.1479 & 1.6852 & 2.2770 \\
\hline
\end{tabular}

\begin{tabular}{|c|c|c|c|c|c|c|c|c|c|}
\hline Drug Name & PRR & ROR & $\chi^{2}$ Test & $95 \% \mathrm{Cl}$ & O/E Ratio & $\begin{array}{l}\text { DM Method } \\
\text { (PRR) }\end{array}$ & $\begin{array}{c}\text { BCPNN } \\
\text { Method (IC- } \\
\text { 2SD value) }\end{array}$ & $\begin{array}{c}\text { Signal } \\
\text { Output } \\
\text { significance }\end{array}$ & p-Value \\
\hline Cyclophosphamide & 4.73 & 4.97 & 236.02 & $1.76 \& 1.34$ & 3.93 & 3.93 & 1.68 & Middle & $<0.001$ \\
\hline
\end{tabular}

\section{Statistical analysis}

As per statistical analysis by SAS version 9.2 software, the Chi square value was observed 253.50 that was higher than 4 (Chi square should be $\geq 4$ as per regulatory guideline for Signal ${ }^{5}$ ) which was further supported by $\mathrm{P}$ value $<0.001$ who showed significant signal of neutropenia associated with cyclophosphamide.

\section{DISCUSSION}

The thalidomide disaster in the early 1960s prompted drug authorities to develop systems for detection of unknown side effects and risks of drugs. Spontaneous reporting systems have since been established in more than 100 countries. Signal detection in spontaneous reporting databases has proven to be a simple and cost effective tool 


\begin{tabular}{|c|c|c|}
\hline System/Organ class & Adverse Reaction & Percentage \\
\hline \multirow{4}{*}{$\begin{array}{l}\text { Blood and lymphatic } \\
\text { system disorders }\end{array}$} & Neutropenia & $5.9 \%$ \\
\hline & Luekopenia & $3.1 \%$ \\
\hline & Thrombocytopenia & $5.7 \%$ \\
\hline & Anemia & $6.8 \%$ \\
\hline \multirow{5}{*}{$\begin{array}{l}\text { General Disorders And } \\
\text { Administrative Site } \\
\text { Conditions }\end{array}$} & Pyrexia & $6.3 \%$ \\
\hline & Fatigue & $1.2 \%$ \\
\hline & Malaise & $1.0 \%$ \\
\hline & Injection site reaction & $0.7 \%$ \\
\hline & Others & $0.2 \%$ \\
\hline \multirow{2}{*}{$\begin{array}{l}\text { Renal And Urinary } \\
\text { Disorders }\end{array}$} & Hemorrhagic cystitis & $8.1 \%$ \\
\hline & Others & $2.1 \%$ \\
\hline \multirow{5}{*}{ Gastro-intestinal disorders } & Nausea/Vomiting & $4.9 \%$ \\
\hline & Diarrhoea & $2.0 \%$ \\
\hline & Stomatitis & $1.1 \%$ \\
\hline & Abdominal Pain & $1.9 \%$ \\
\hline & Mucosal Ulceration & $0.2 \%$ \\
\hline $\begin{array}{l}\text { Metabolism and Nutririon } \\
\text { Disorder }\end{array}$ & Anorexia & 0.5 \\
\hline Cardiovascular Disorder & Cardiactoxicity & $8.1 \%$ \\
\hline \multirow{4}{*}{ Central Nervous System } & CNSToxicity & $1.4 \%$ \\
\hline & $\begin{array}{l}\text { Peripheral } \\
\text { neuropathy }\end{array}$ & $0.5 \%$ \\
\hline & Dizziness & $4.3 \%$ \\
\hline & Parasthesia & $1.6 \%$ \\
\hline \multirow{3}{*}{$\begin{array}{l}\text { Skin and subcutaneous } \\
\text { tissue disorders }\end{array}$} & Alopecia & $3.5 \%$ \\
\hline & Skin Rash & $7.3 \%$ \\
\hline & Skin Pigmentation & $0.8 \%$ \\
\hline \multirow{3}{*}{$\begin{array}{l}\text { Respiratory, thoracic and } \\
\text { mediastinal disorders }\end{array}$} & Dyspnea & 5.3 \\
\hline & Cough & 2.2 \\
\hline & Others & 1.4 \\
\hline $\begin{array}{l}\text { Musculoskeletal and } \\
\text { connective tissue disorders }\end{array}$ & \multicolumn{2}{|l|}{$3.4 \%$} \\
\hline Infection and Infestation & \multicolumn{2}{|l|}{$8.5 \%$} \\
\hline
\end{tabular}

for identifying suspected new adverse drug reactions. Some of the better known examples of safety signals detected include apart from phocomelia from thalidomide during pregnancy, vaginal clear cell cancer in girls of mothers using diethylstilbestrol during pregnancy, suicidal ideation and suicide induced by the anti-obesity drug rimonabant and the latest example; narcolepsy in relation to the pandemic vaccine Pandemrix. ${ }^{9}$

The spontaneous reporting systems differ by country regarding accepted reporters (e.g., physicians, pharmacists, consumers) and the managing of the systems (national authorities, university based or independent institutions). A few standardized terminologies for coding adverse events and drugs are applied, which lend the opportunity to assemble and analyzed information from different sources to detect and act on new safety signals. The original signal detection method of case-by-case assessment of spontaneous reports of adverse drug reactions (ADR) is effective, but resource consuming, especially in large ADR databases with high volumes of incoming reports. ${ }^{9}$

This has led to the development and acceptance of semiautomated signal detection methods, including primary step(s) of detection by statistical Disproportionality analysis, followed by manual clinical validation. Several statistical methods are currently in use. ${ }^{7-10}$ but no gold standard has been established. ${ }^{10-11}$ The methods have the ability to detect new safety signals for drugs years earlier than traditional manual methods. ${ }^{12-13}$ Strengths, limitations and differences between different pharmacovigilance signal detection methods including their initial disproportionality part have been analyzed and described previously (CIOMS 2010). Within the European Union (EU) signal detection is continuously performed in the common ADR database EudraVigilance (EV, EV2013) using the Proportional Reporting Ratio (PRR) method., ${ }^{9,10,14-16}$

The values of PRR (4.73), ROR (4.97), PRR calculated by chi-square statistics (236.02), 95\% confidence interval of PRR (1.34 \& 1.76), O/E ratio (3.93), PRR by Du-Mouchel method (3.93) suggest toxic signal for neutropenia. Further, the value of IC-2SD value was 1.68 for cyclophosphamide which also suggest middle intensity for neutropenia associated with cyclophosphamide.

\section{CONCLUSION}

The therapeutic class specific signal of neutropenia coupled with cyclophosphamide was found potent enough to cause neutropenia.

\section{ACKNOWLEDGEMENT}

The authors thank to Mr. Hardik Dodiya for his support throughout the conduct of study.

\section{CONFLICTS OF INTEREST}

The authors declare that they have no conflict of interest. 


\section{Highlights of Paper}

- The PRR value was 4.7396 which was $\geq 2$ as per regulatory criterion indicates signal for neutropenia induced by cyclophosphamide.

- PRR calculated by chi-square statistics was 236.02518 and $95 \% \mathrm{Cl}$ of PRR was found to be 1.3484 (lower limit) and 1.7634 (higher limit) indicate important signal for neutropenia caused by cyclophosphamide. As per regulatory criteria, if chi-square calculated PRR is $\geq 4$ and lower limit of $95 \% \mathrm{Cl}$ of PRR is $\geq 1$, then it is considered as significant signal.

- The value of IC-2SD is observed 1.6852 for cyclophosphamide means middle signal for cyclophosphamide-induced neutropenia (IC-2SD $\geq 0$ ).

\section{Author Profile}

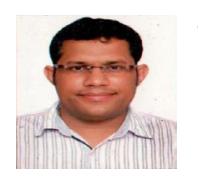

- Sharwan Singhal: Presently studying as a student at Nirma University. Previously, I worked with Cadila Pharmaceuticals Limited, Ahmedabad. He had 3 nos. of journal paper.

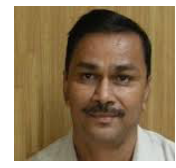

- Dr. Bhaswat Chakraborty: Is currently 2005 to 2010 a Senior VP Research Development of Cadila Pharmaceuticals Ltd, Ahmedabad, Gujarat, India where he is responsible for Clinical Pharmacology Clinical Trials Ph IIV. Bioequivalence Trials Preclinical Studies Bioinformatics and Data Management. He is also an Adjunct Faculty of Albany College of Pharmacy and Health Sciences Albany New York USA; Editorial Board Member Journal of Bioequivalence Bioavailability; PhD Guide and External Examiner to a number of Universities in India. He has been a reviewer for several international journals and member of Ethics Committee and DSMB Dr Chakraborty received his PhD 1987 in Clinical Pharmacology from University of Sakatchewan, Canada. He served as a Senior Safety and Efficacy Reviewer 1989 to 1997 and Acting Division Chief at the Therapeutic Drugs Directorate Canadian FDA, Ottawa, Canada. Dr. Chakraborty also served as the Director of Biopharmaceutics 1997 to 2000 Biovail Contract Research Toronto, Canada and President of Foresee Consultant until the present assignmentHe is founder of a Spiritual Association. Dr. Chakraborty has more than 60 research papers and abstracts in peer reviewed journals. He has received many merit awards and AAPS Visiting Scientist Awards.

\section{REFERENCES}

1. Meyboom RHB, Lindquist M, Egberts ACG, Edwards IR. Signal selection and follow-up in pharmacovigilance. Drug Safety 2002; 25(6): 459-65.

2. Emadi A, Jones RJ, Brodsky RA. Cyclophosphamide and cancer: golden anniversary. Nat Rev Clin Oncol. 2009; 6(11): 638-47.

3. Health Canada: Available from:http://www.hc-sc.gc.ca/index-eng. php (dated 15/April/2013).

4. Norén GN. Statistical methods for knowledge discovery in adverse drug reaction surveillance typeset by LATEX, Department of Mathematics, Stockholm University, Stockholm: 2007; 1-41. Available from: http://www.diva-portal.org/smash/get/ diva2:197004/FULLTEXT01.pdf.

5. Eudravigilance Expert Working Group (EV-EWG), European Medicine Agency Guidelines, London 26 June 2008, Doc. Ref. EMEA/106464/2006 rev. 1, p. 1-22.

6. Health Canada: Canadian Adverse Event Reporting Program Available from: Http://www.CADRMP/index_e.jsp.

7. Health Canada: Canadian Adverse Event Reporting Program Available from: www.hc-sc.gc.ca/ahc-asc/activit/atip-aiprp/privprot/pia-efvp-a-eng.php.

8. Bate A, Lindquist M, Edwards IR, Orre R. A data mining approach for signal detection and analysis. Drug Safety 2002; 25(6): 393-7.

9. Finney DJ. Systemic signaling of adverse reactions to drugs. Methods Inf Med. 1974; 13(1): 1-10.

10. Evans SJ, Waller PC, Davis S. Use of proportional reporting ratios (PRRs) for signal generation from spontaneous adverse drug reaction reports Pharmacoepidemiol Drug Safety 200; 10(6): 483-86.

11. Szarfman A, Machado SG, O'Neill RT. Use of screening algorithms and computer systems to efficiently signal higher-than expected combinations of drugs and events in the US FDA's spontaneous reports database. Drug Safety 2002; 25(6): 381-92.

12. Bate A, Lindquist M, Edwards IR, Olsson S, Orre R, Lansner A, et al. A Bayesian neural network method for adverse drug reaction signal generation. Eur J Clin Pharmacol. 1998; 54(4): 315-21.

13. Van Puijenbroek EP, Bate A, Leufkens HG, Lindquist M, Orre R, Egberts AC. A comparison of measures of disproportionality for signal detection in spontaneous reporting systems for adverse drug reactions. Pharmacoepidemiol Drug Safety 2002; 11(1): 3-10.

14. Hochberg AM, Hauben M, Pearson RK, O'Hara DJ, Reisinger SJ, Goldsmith DI, et al. An evaluation of three signal-detection algorithms using a highly inclusive reference event database. Drug Safety 2009; 32(6): 509-25.

15. Hauben M, Reich L, Chung S. Postmarketing surveillance of potentially fatal reactions to oncology drugs: potential utility of two signal-detection algorithms. Eur J Clin Pharmacol. 2004; 60(10): 747-50.

16. Alvarez Y, Hidalgo A, Maignen F, Slattery J. Validation of statistical signal detection procedures in eudravigilance postauthorization data: a retrospective evaluation of the potential for earlier signaling. Drug Safety 2010; 33(6): 475-87. 